\title{
PLANTS
}

\section{NATURE'S FURY}

DAISY D. MEYERS, Box 218, Leader, Saskatchewan. SON $1 \mathrm{HO}$

The violent wind and rain storm in the late evening of 29 July 1993 covered a large area from Leader and Prelate in the south to the Tramping Lake-Kerrobert region in central Saskatchewan. Pictured is a large Manitoba Maple tree 62 in. in circumference and over $30 \mathrm{ft}$. long. It was one of the many trees and bushes uprooted or damaged on Meyer's ranch at Leader. No loss of animal or bird life was observed locally although any bird nests, eggs or nestlings would be unlikely to survive the storm. Loss of suitable habitat may have an impact on tree nesting birds in 1994.

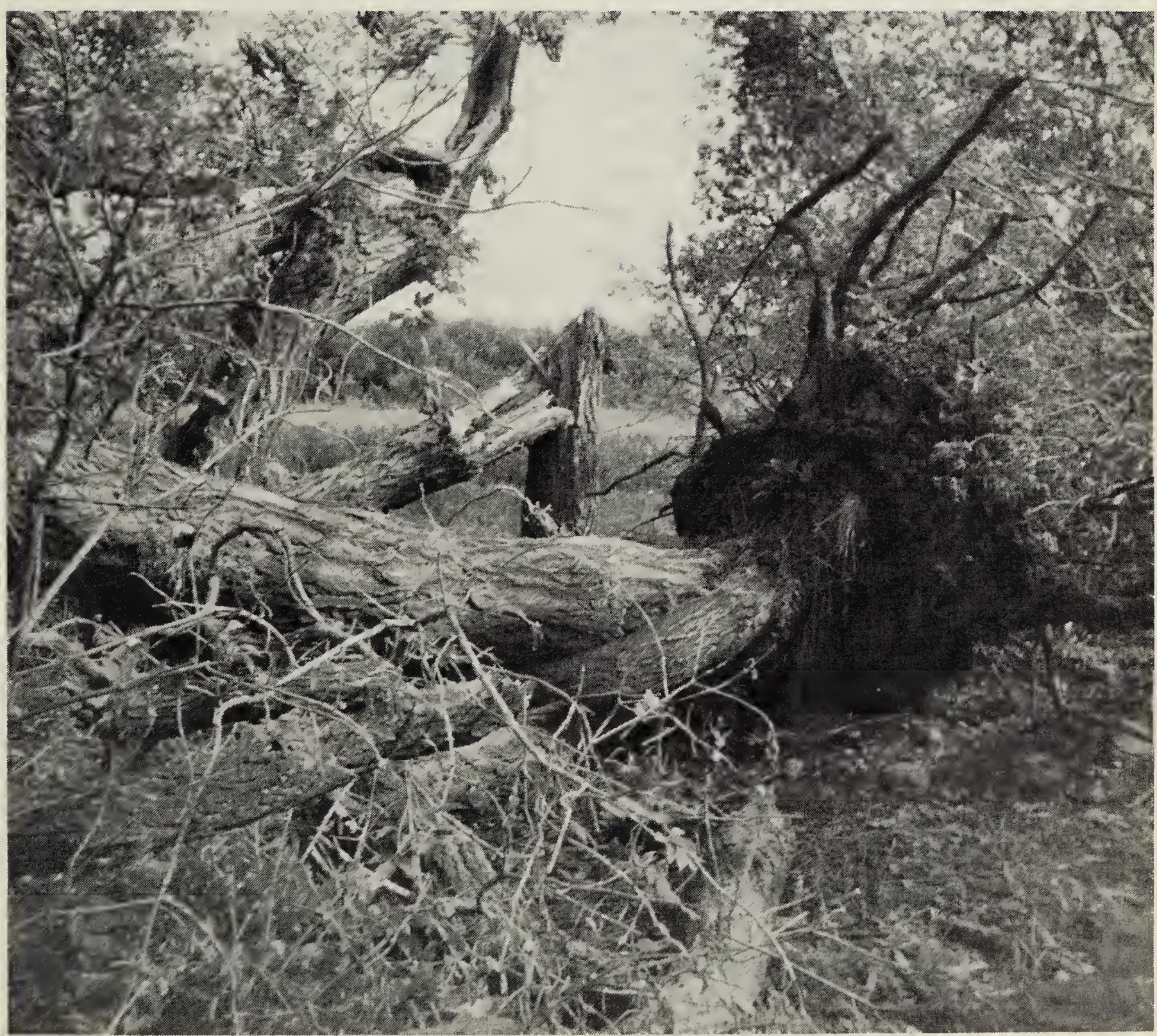

Manitoba Maple uprooted on Meyers ranch by the storm of 29 July 1993. 